\title{
Influencia de la altura en los niveles de proteína $C$ reactiva en adultos con adiposidad visceral abdominal
}

Luis Arteaga-Temoche ${ }^{1, a}$, Carmen Ayala-Jara ${ }^{2, b}$, Ericson Castillo Saavedra ${ }^{3, b}$, Luis Seclén-Ayala ${ }^{4, a}$, Junior Merino Ramírez ${ }^{4, a}$, David Simón Cruz ${ }^{4, a}$, Aníbal Trujillo Gallardo ${ }^{4, a}$, Rómulo Shimizu Varas ${ }^{4, a}$, Jhoel Zúñiga Luna ${ }^{4, a}$, Guillermo Vallejo Zárate ${ }^{4, a}$, Joseph Zambrano Quispe ${ }^{4, a}$, Jesús Julca Carranza ${ }^{4, a}$, Fernando Samamé Minchón ${ }^{4, a}$, Nicolás Mattos Campos ${ }^{4, a}$, Kevin Aldave Lázaro 4,a , Henry Charcape Aliaga ${ }^{4, a}$, Antonio Meléndez Vargas ${ }^{4, a}$

\section{RESUMEN}

Objetivo: Evaluar la influencia de la altura en los niveles de proteína $C$ reactiva (PCR) en adultos con adiposidad visceral abdominal.

Materiales y métodos: Se realizó un estudio cuantitativo con diseño cuasi-experimental, que incluyó veinticuatro estudiantes de medicina de la Universidad Nacional de Trujillo, sexo masculino, seleccionados de manera no probabilística por conveniencia y sujeto participante, que fueron evaluados a 0 y $4386 \mathrm{~m} \mathrm{~s}$. $\mathrm{n}$. $\mathrm{m}$. y clasificados de acuerdo al grado de adiposidad visceral abdominal: normal (G1) y elevada (G2).

Resultados: El nivel de PCR de G1 en relación a G2 no tuvo diferencia significativa. Respecto a los niveles de PCR de G2 se empleó la prueba no paramétrica de Wilcoxon y para G1 se usó la prueba T-student, evidenciándose una significancia en ambos casos.

Conclusiones: Las variaciones de los niveles de PCR en altura con respecto al basal de ambos grupos fueron significativos.

Palabras clave: Proteína C; adiposidad; altitud (Fuente: DeCS BIREME).

\section{Influence of high altitude on C-reactive protein levels in adults with abdominal visceral adiposity}

\section{ABSTRACT}

Objective: To evaluate the influence of high altitude on C-reactive protein (CRP) levels in adults with abdominal visceral adiposity.

Materials and methods: A quantitative study with quasi-experimental design, which included twenty-four (24) male medical students from the National University of Trujillo, selected by non-probability convenience sampling and study subject, evaluated at 0 and 4,386 m.a.s.l., and classified according to their degree of abdominal visceral adiposity: normal (G1) and high (G2).

Results: The CRP level of G1 in relation to G2 showed no significant difference. Regarding CRP levels, Wilcoxon rank-sum (non-parametric) test was used for G2 and Student's t-test was used for G1, with significance being shown in both cases. Conclusions: Variations on CRP levels in high altitude compared to sea level in both groups were significant.

Keywords: Protein C; adiposity; altitude (Source: MeSH NLM).

1. Médico Cirujano.

2. Doctorado en Farmacia y Bioquímica, Químico Farmacéutico.

3. Doctorado en Ciencias Biomédicas, Químico Farmacéutico.

4. Estudiante Medicina.

a. Universidad Nacional de Trujillo, Facultad de Medicina. Trujillo, Perú.

b. Universidad Nacional de Trujillo, Facultad de Farmacia y Bioquímica .Trujillo, Perú. 


\section{INTRODUCCIÓN}

Las células de nuestro organismo requieren de una homeostasis de oxígeno óptima para mantener las funciones vitales. El proceso fisiológico incluye la entrada de oxígeno a través de los pulmones, luego los eritrocitos sirven como vehículo de transporte hacia los sistemas vasculares, y finalmente mediante un dispositivo de propulsión como el corazón lo distribuye hacia las células del organismo ${ }^{(1)}$.

La proteína $C$ reactiva $(P C R)$ es una proteína de fase aguda, altamente sensible como marcador prototipo de la inflamación y/o infección general en los seres humanos. Miembro de una familia de proteínas altamente conservadas denominada pentraxinas, es producida en muchas células del cuerpo, principalmente por los hepatocitos y células del endotelio vascular en respuesta a la presencia de las citocinas que fomentan la inflamación. La PCR de alta sensibilidad (PCRas) es utilizada como un predictor para el desarrollo de eventos cardiovasculares ${ }^{(2,3)}$.

La grasa visceral, contenida en la parte interna de las cavidades corporales, envolviendo órganos, sobre todo abdominales, está constituida por adipocitos de un tamaño más reducido, con menor capacidad de almacenamiento, es más vascularizado, y tiene mayor inervación simpática y gran número de receptores $\mathrm{B3}$-adrenérgicos, lo que facilita una mayor actividad metabólica. El tejido adiposo almacena grasa en forma de triacilglicerol que se asocia, entre otros procesos, con la activación de las vías inflamatorias. La mayor concentración de ácidos grasos libres y de los productos de degradación inducen la liberación de citoquinas proinflamatorias participantes de la inflamación ${ }^{(4)}$.

En la actualidad, la obesidad se ha relacionado con niveles elevados de PCR como marcador de la inflamación y predictor de riesgo cardiovascular y ateroesclerosis ${ }^{(5,6,7)}$. Recientes estudios epidemiológicos han demostrado asociación entre los niveles séricos elevados de PCR con obesidad, adiposidad visceral, y resistencia a la insulina, lo que sugiere que un estado inflamatorio crónico se asocia con la hiperglucemia y la diabetes a través de la obesidad o aumento de la resistencia a la insulina ${ }^{(8)}$.

La altitud es un factor que predispone a la persona a cambios fisiológicos adaptativos, por lo que a nivel celular, la adaptación a la hipoxia se realiza por un incremento en la eficiencia de las vías generadoras de energía, principalmente mediante el incremento de la actividad de la glucólisis anaeróbica, y por otro lado, por una disminución en el consumo de energía durante los procesos fisiológicos ${ }^{(1)}$. En este sentido, el estudio evidenció la influencia de la altitud sobre los niveles de PCR en adultos con adiposidad visceral abdominal.

\section{MATERIALES Y MÉTODOS}

El estudio es cuasiexperimental con preprueba, postprueba y grupos de control intactos. Se consideró una muestra total de 24 adultos, de sexo masculino y estudiantes de medicina de la Universidad Nacional de Trujillo, seleccionados por muestreo no probabilístico de conveniencia y sujeto participante, clasificados de acuerdo al grado de adiposidad visceral abdominal: normal (G1) y elevada (G2).

Los participantes en el estudio fueron clasificados de acuerdo al grado de adiposidad visceral abdominal, utilizando el método de Impedancia Bioeléctrica. La muestra biológica fue sangre periférica, a partir de la cual se cuantificaron los niveles de PCR mediante el método inmunoturbidimétrico con látex. Se consideraron las siguientes variables: la altura, que es la distancia vertical entre un punto determinado en el espacio y otro punto tomado como referencia, expresada en metros; $y$, el nivel de PCR que es la medición cuantitativa de la concentración expresada en $\mathrm{mg} / \mathrm{L}$.

Los datos obtenidos de PCR fueron analizados estadísticamente mediante la prueba de Shapiro-Wilk, prueba T para la igualdad de medias, prueba U de MannWhitney para muestras independientes y la prueba de Wilcoxon de los rangos con signo para muestras relacionadas. Los programas utilizados para el análisis de las variables fueron Microsoft Excel 2010 y el software Statistical Package for the Social Sciences versión 22.

El estudio fue autorizado por el Comité Institucional de Ética en Investigación de la Universidad Nacional de Trujillo. Todos los participantes fueron informados sobre los propósitos de la investigación, procedimientos y posibles riesgos, obteniéndose la firma del consentimiento informado a través del cual aceptaron voluntariamente participar en el estudio.

\section{RESULTADOS}

El estudio demuestra que mediante la prueba de ShapiroWilk los datos de PCR de G1 y G2 obtenidos en Chimborazo, no se ajustaban a una distribución normal $(-p<0.05)$, por lo que se utilizó la prueba no paramétrica de MannWhitney para su análisis. En este sentido, en la figura 1 se evalúa la variación de los niveles de PCR de G1 obtenidos en Chimborazo y Trujillo, para lo cual se aplicó la prueba Tstudent, obteniendo un valor $-p=0,005 / 2=0,0025<0,05$; y reflejaría que las muestras obtenidas de los participantes a nivel del mar y en el Chimborazo son estadísticamente significativas (Figura 1). 
Luis Arteaga Temoche, Carmen Ayala Jara, Ericson Castillo Saavedra, Junior Merino Ramírez, David Simón Cruz, Ernesto Seclén Ayala, Aníbal Trujillo Gallardo, Rómulo Shimizu Varas, Jhoel Zúñiga Luna, Guillermo Vallejo Zárate, Joseph Zambrano Quispe, Jesús Julca Carranza, Fernando Samamé Minchón, Nicolás Mattos Campos, Kevin Aldave Lázaro, Henry Charcape Aliaga, Antonio Meléndez Vargas

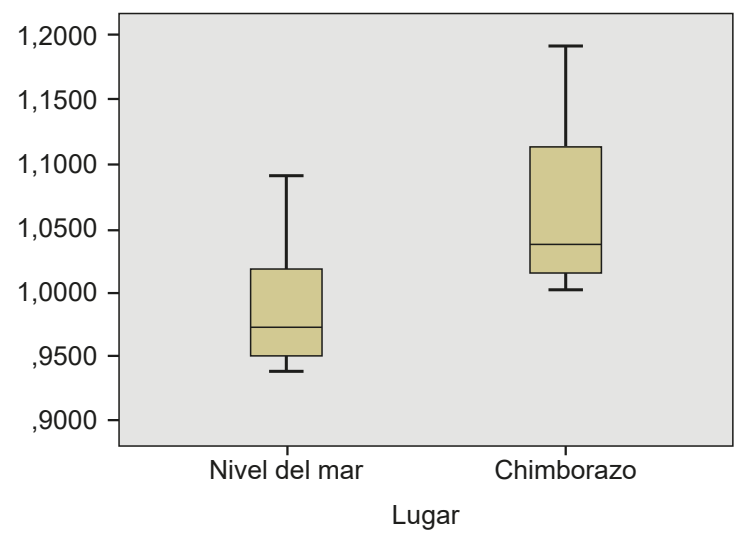

Figura 1. Niveles de PCR de G1 en Trujillo y Chimborazo

Para evaluar la variación de los niveles de PCR de G2 entre Chimborazo y Trujillo se aplicó la prueba de Wilcoxon de los rangos con signos para muestras relacionadas, obteniendo un valor $-p=0,015 / 2=0,0075<0,05$; que demostraría la diferencia estadísticamente significativa entre los datos obtenidos a nivel del mar y en el Chimborazo (Figura 2).

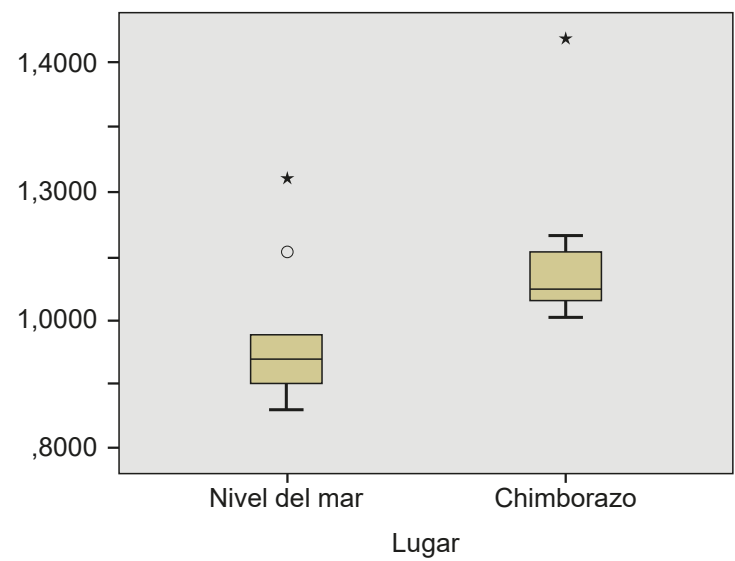

Figura 2. Niveles de PCR de G2 en Trujillo y Chimborazo

Los niveles de PCR en pacientes con adiposidad visceral abdominal G1 y G2 no fueron estadísticamente significativas (0,57 $>0,05)$ cuando las muestras sanguíneas periféricas fueron extraídas en Trujillo, lo cual permite inferir que los grupos de estudio fueron evaluados en condiciones de homogeneidad, incrementando de esta manera, la confiabilidad de los datos obtenidos (Tabla 1).

Tabla 1. Prueba de muestras independientes de G1 y G2 en Trujillo

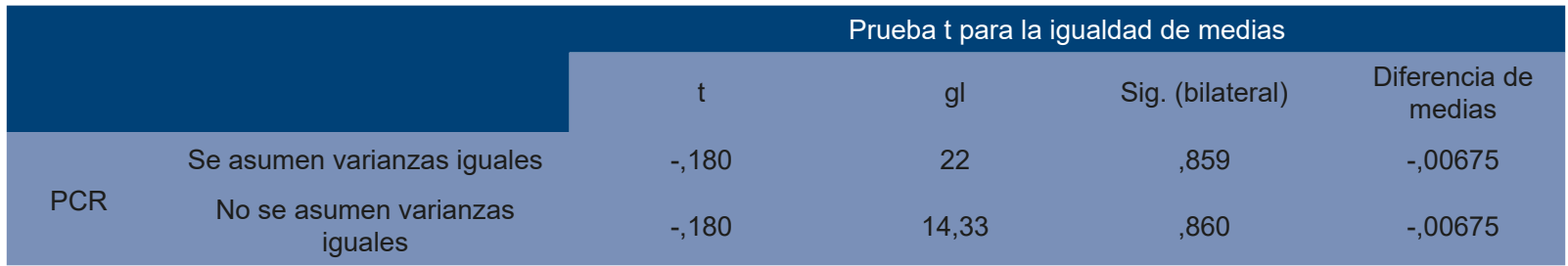

Valor- $\mathrm{p}=1-(0,86 / 2)=0,57>0,05$ 
Se observa que cuando los datos fueron obtenidos de Chimborazo mediante la prueba $U$ de Mann-Withney para muestras independientes, no existió diferencia estadísticamente significativa $(0,303>0,05)$, evidenciando que a medida que se incrementa la altura, de manera proporcional se estaría elevando los niveles de PCR, tanto en los participantes con adiposidad visceral abdominal G1 y G2 (Tabla 2).

Tabla 2. Prueba de muestras independientes de G1 y G2 en Chimborazo

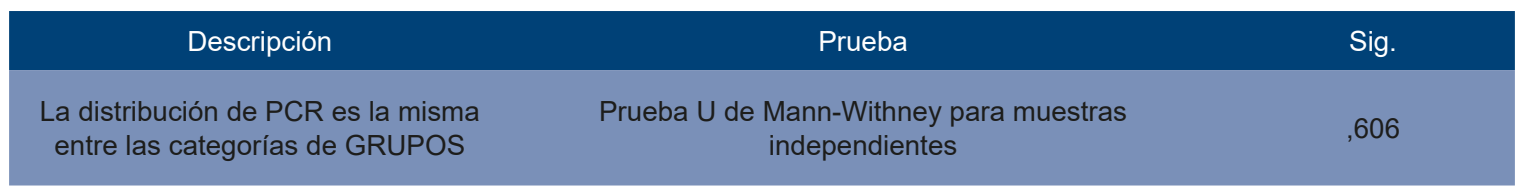

Valor $-\mathrm{p}=0,606 / 2=0,303>0,05$

Se evidencia diferencia estadísticamente significativa $(0,0025<0,05)$ entre los grupos de participantes con adiposidad visceral abdominal G1 y G2, y estaría representando la influencia de la altura sobre los niveles de PCR, y sobre los procesos mediados por factores proinflamatorios (Tabla 3 ).

Tabla 3. Prueba de muestras emparejadas en Trujillo y Chimborazo

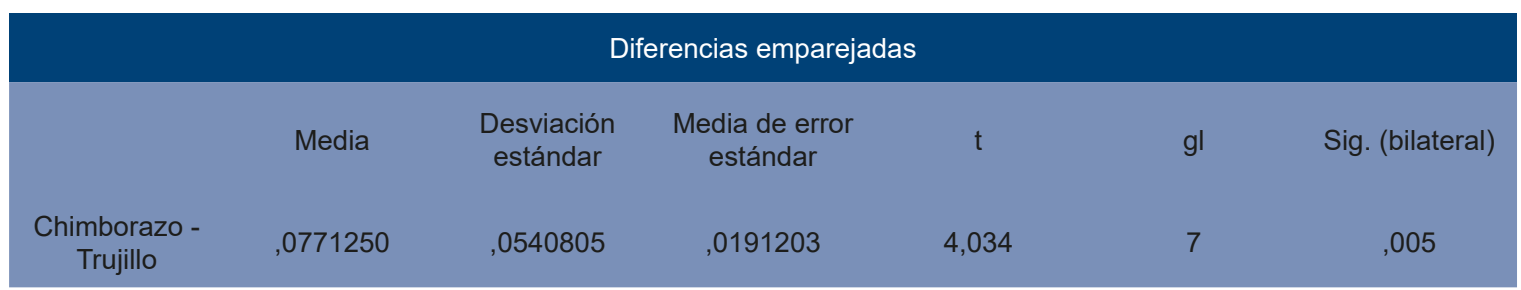

Valor $-\mathrm{p}=0,005 / 2=0,0025<0,05$

\section{DISCUSIÓN}

La diferencia significativa encontrada en la Figura 1 sugiere que el grupo con adiposidad visceral normal expuesto a 4386 m s.n.m (Chimborazo) induce una mayor respuesta inflamatoria en las células inmunes y endoteliales respecto al grupo evaluado en Trujillo. La variación de los niveles de PCR de G1 en relación a la altura, evidencian una diferencia significativa en Chimborazo con respecto al basal en Trujillo, el valor $-\mathrm{p}=0,005 / 2=0,0025<0,05$ obtenido por la prueba paramétrica T-student, indicó que existen razones suficientes al nivel del 0,05 para afirmar que el incremento de PCR de Trujillo a Chimborazo fue significativo en los estudiantes con adiposidad visceral abdominal normal (G1). Esta variación refleja que ambas gráficas son asimétricas positivas, lo que indica evidentemente que en Chimborazo hay mayor incremento del nivel de PCR.

La hipoxia presentada por los participantes del grupo G1 se manifestó por una disminución en la disponibilidad de oxígeno, diversos sistemas quimiosensoriales actuaron rápidamente modulando la ventilación pulmonar y la perfusión de la circulación sanguínea, optimizando el suministro de oxígeno para el metabolismo de tejidos, con un incremento moderado de los niveles de PCR ${ }^{(1)}$.

Diversos estudios han asociado una proporcionalidad directa entre los niveles de PCR y el grado de adiposidad visceral, por lo que en la Figura 2 se observaría un incremento significativo en los niveles de PCR, lo cual representaría que la hipoxia produciría cambios en la expresión génica mediados por factores de transcripción como el receptor antagonista de la interleucina 1 (IL-1ra), factor de necrosis tumoral (FNT) y el factor nuclear de interleucina 6 (IL-6) (9-13).

De la misma forma, se analizó la variación de los niveles de PCR de G2 en relación a la altura, se encontró que el valor $-p=0,015 / 2=0,0075<0,05$ obtenido mediante la prueba no paramétrica de Wilcoxon de los rangos con signo, indicó que existen razones suficientes al nivel del 0,05 para afirmar que el cambio de PCR de Trujillo a Chimborazo fue significativo en los participantes con adiposidad visceral abdominal elevada (G2). La gráfica es simétrica, pero presenta valores atípicos, sin embargo, en Chimborazo la gráfica es asimétrica positiva, lo que comprueba evidentemente que en Chimborazo hay mayor incremento del nivel de PCR con presencia de un valor atípico. Por lo tanto, se demuestra que la exposición a la altura fue determinante en la variación del nivel de PCR tanto de G1 como de G2.

Haagobian et al ${ }^{(14)}$, Hartmann et al ${ }^{(15)}$ y Tomita et al ${ }^{(16)}$ documentaron la asociación entre la hipoxia y la PCR mediada por la liberación de IL -6, por lo que los participantes con adiposidad visceral abdominal elevada tendrían niveles incrementados de PCR, y asociado a la disminución de la presión parcial de oxígeno, los valores circulantes de IL-6, IL-1ra y PCR son incrementados en respuesta a la hipoxia 
Luis Arteaga Temoche, Carmen Ayala Jara, Ericson Castillo Saavedra, Junior Merino Ramírez, David Simón Cruz, Ernesto Seclén Ayala, Aníbal Trujillo Gallardo, Rómulo Shimizu Varas, Jhoel Zúñiga Luna, Guillermo Vallejo Zárate, Joseph Zambrano Quispe, Jesús Julca Carranza, Fernando Samamé Minchón, Nicolás Mattos Campos, Kevin Aldave Lázaro, Henry Charcape Aliaga, Antonio Meléndez Vargas

en condiciones a gran altura, lo cual puede reflejar una considerable inflamación local.

En las tablas 1 y 2 se aprecia que los participantes con adiposidad visceral normal (G1) y elevada (G2) no presentan diferencia significativa cuando fueron expuestos a Trujillo y Chimborazo, y reflejaría que el proceso inflamatorio producido es de baja intensidad. Por tanto, en el tejido adiposo, no sólo los macrófagos que lo forman, sino los propios adipocitos, tienen capacidad de producir factores proinflamatorios. Los adipocitos, al igual que los macrófagos, a través de la estimulación de receptores sensibles a agentes patógenos o de mediadores de inflamación, estimulan múltiples cascadas de señalización que llevan, finalmente, a la secreción tanto de citoquinas como de proteínas de fase aguda ${ }^{(17)}$.

Algunos autores refieren que la inflamación es consecuencia de la obesidad, se sugiere también que la obesidad se puede producir como consecuencia de un proceso inflamatorio $(10,11,12)$. Los adipocitos y los macrófagos comparten varias características, dentro de ellas los productos de expresión de sus genes y su capacidad funcional, ya que los macrófagos pueden almacenar lípidos y los preadipocitos exhibir propiedades fagocíticas y antimicrobianas, llegando a poder diferenciarse en macrófagos ${ }^{(4,11,12)}$.

En la tabla 3 se observa diferencia significativa cuando se analizaron las muestras emparejadas de los participantes tanto en Trujillo como Chimborazo, lo que explicaría una relación directa entre el índice de masa corporal y los niveles de PCR, IL-6, inhibidor del plasminógeno tisular (PAI-1), moléculas de adhesión (P-selectina, ICAM, VCAM1) y factores quimiotácticos (MCP-1), los que favorecen la adhesión, migración y acumulación de monocitos y linfocitos $\mathrm{T}$ en el espacio subendotelial a consecuencia de la alteración de la permeabilidad vascular ${ }^{(4)}$.

El tejido adiposo de los sujetos obesos se encuentra infiltrado por una cantidad significativamente superior de macrófagos que en los individuos normopesos. Estos macrófagos posiblemente son atraídos al tejido adiposo debido a la muerte de adipocitos hipertrofiados o por la secreción de citoquinas proinflamatorias. Durante la obesidad, el tejido adiposo secreta grandes cantidades de adipoquinas creando así un ambiente proinflamatorio, se producen en mayor cantidad en el tejido adiposo visceral que en el subcutáneo. Asimismo, en la obesidad existe un estado de estrés oxidativo caracterizado por elevadas cantidades de especies reactivas de oxígeno, el cual se ha asociado con la resistencia a la insulina y con la diabetes mellitus y adicionalmente permiten perpetuar el ambiente inflamatorio típico de la obesidad, ya que mediante la activación del factor nuclear potenciador de las cadenas ligeras kappa de las células B (NF-kB) se estimula la expresión de genes que codifican para proteínas y moléculas involucradas en el proceso inflamatorio ${ }^{(17)}$.

\section{Contribuciones de autoría}

LAT, CAJ y ECS participaron en la concepción y diseño del estudio, recolección de datos, análisis e interpretación de datos, redacción del artículo, revisión crítica del artículo y aprobación de su versión final. JMR, DSC, ESA, ATG, RSV, JZL, GVZ, JZQ, JJC, FSM, NMC, KAL, HCHA Y AMV participaron en la concepción y diseño del estudio, recolección de datos, análisis e interpretación de datos.

\section{REFERENCIAS BIBLIOGRÁFICAS}

1. Michiels C. Physiological and Pathological Responses to Hypoxia. AJP. 2004; 164(6): 1875-82. Disponible en: https://www.ncbi.nlm.nih.gov/pubmed/15161623

2. Acevedo M, Arnáiz P, Barja S, Bambs C, Berrios X, Guzmán $B$, et al. Proteína $C$ reactiva y su relación con adiposidad, factores de riesgo cardiovascular y aterosclerosis subclínica en niños sanos. Rev Esp Cardiol. 2007; 60(10): 1051-8. Disponible en: http://www.revespcardiol.org/ es/proteina-c-reactiva-su-relacion/articulo/13111237/

3. Devaraj S, Singh U, Jialal I. Evolución del papel de la proteína $C$ reactiva en aterotrombosis. Química Clínica. 2009; 55(2): 229-238.

4. Manzur F, Alvear C, Alayón A. Adipocitos, obesidad visceral, inflamación y enfermedad cardiovascular. Rev Colom Cardiol. 2010; 17(5): 210. Disponible en: https: / / www.sciencedirect.com/science/article/pii / S0120563310702436

5. Irkulla S, Ujam B, Gaze D, Kumar D, Mendall M. Abdominal adiposity is the main determinant of the $\mathrm{C}$-reactive response to injury in subjects undergoing inguinal hernia repair. J Inflamm. 2013; 10(5):1-9. Disponible en: https://www.ncbi.nlm.nih.gov/pmc/ articles/PMC3579693/

6. Tsuriya D, Morita H, Morioka T, Takahashi N, Ito T, Oki Y, et al. Significant correlation between visceral adiposity and high-sensitivity C-reactive protein (hs-CRP) in Japanese subjects. Intern Med. 2011; 50(22):2767-73. Disponible en: https: / / www.ncbi.nlm.nih.gov/pubmed/22082888

7. Saijo Y, Kiyota N, Kawasaki Y, Miyazaki Y, Kashimura J, Fukuda M, et al. Relationship between C-reactive protein and visceral adipose tissue in healthy Japanese subjects. Diabetes Obes Metab. 2004; 6(4):249-58. Disponible en: https: / / www.ncbi.nlm.nih.gov/pubmed/15171748

8. Forouzan Z, Leila P, Soheila Y, Fatemeh A. Relationships between human serum $C$ reactive protein, glucose concentration and insulin sensitivity in obese or overweight women. J. Bio. \& Env. Sci. 2014; 4(2): 256-61. Disponible en: http://www.innspub.net/wp-content/ uploads/2014/03/JBES-Vol4No1-p256-261.pdf

9. Cannon B, Nedergaard J. Brown adipose tissue: function and physiological significance. Physiol Rev. 2004; 84(1): 277-359. Disponible en: http://www.physiology.org/doi/ abs/10.1152/physrev.00015.2003

10. Kim K, Valentine J, Shin Y, Gong K. Associations of visceral adiposity and exercise participation with $\mathrm{C}$-reactive protein, insulin resistance, and endothelial dysfunction in Korean healthy adults. Metabolism. 2008; 57(9):1181-9. Disponible en: http://www.sciencedirect. com/science/article/pii/S0026049508001406

11. Tsuriya D, Morita H, Morioka T, Takahashi N, Ito T, Oki Y, et al. Significant correlation between visceral adiposity and high-sensitivity C-reactive protein (hs-CRP) in Japanese subjects. Intern Med. 2011; 50(22):2767-73. Disponible en: https://www.jstage.jst.go.jp/article/ internalmedicine/50/22/50_22_2767/_article/-char/ja/

12. Saijo Y, Kiyota N, Kawasaki Y, Miyazaki Y, Kashimura J, Fukuda M, et al. Relationship between C-reactive protein 
and visceral adipose tissue in healthy Japanese subjects. Diabetes Obes Metab. 2004; 6(4):249-58. Disponible en: http: / / onlinelibrary.wiley.com/doi/10.1111/j.14628902.2003.0342.x/full

13. Bouloukaki I, Mermigkis Ch, Kallergis E, Moniaki V, Mauroudi E, Schiza S. Obstructive sleep apnea syndrome and cardiovascular disease: The influence of C-reactive protein. World J Exp Med. 2015; 5(2): 77-83. Disponible en: https://www.ncbi.nlm.nih. $\mathrm{gov} / \mathrm{pmc} /$ articles/PMC4436942/

14. Hagobian T, Jacobs K, Subudhi A, Fattor J, Rock P, Muza S, et al. Cytokine response at high altitude: effects of exercise and antioxidants at $4300 \mathrm{~m}$. Med Sci Sports Exerc. 2006; 38(2):276-85. Disponible en: http://digitalcommons.calpoly. edu/kine_fac/36/

15. Hartmann G, Tschöp M, Fischer R, Bidlingmaier C, Riep $R$, Tschöp $K$, et al. High altitude increases circulating Interleukin-6, Interleukin-1 receptor antagonist and C-reactive protein. Cytokine, 2000; 12(3):246-52. Disponible en: http://www.sciencedirect.com/science/article/pii/ S1043466699905331

16. Tomita H, Takamuro M, Soda W, Hatakeyama K, Tsutsumi $\mathrm{H}$. Increased serum high-sensitivity C-reactive protein is related to hypoxia and brain natriuretic peptide in congenital heart disease. Pediatr Int. 2008; 50(4):436-40. Disponible en: http://onlinelibrary.wiley.com/doi/10.1111/j.1442200X.2008.02581.x/full

17. Acosta E. Obesidad, tejido adiposo y resistencia a la insulina. Acta Bioquím Clín Latinoam. 2012; 46 (2): 183 94. Disponible en: http://www.scielo.org.ar/scielo. php?script=sci_arttext\&pid=S0325-29572012000200003
Fuentes de financiamiento:

El presente ha sido financiado por los autores y la Universidad Nacional de Trujillo (UNT). No obstante, el presente artículo no constituye un posicionamiento institucional oficial por parte de la UNT.

Conflictos de interés:

Los autores declaran no tener conflictos de interés.

\section{Correspondencia:}

Ericson Felix Castillo Saavedra

Dirección: Universidad Nacional de Trujillo. Av. Juan Pablo II S/N. Trujillo, Perú.

Teléfono: 979127933

Correo electrónico: ericson_fcs@hotmail.com

Recibido: 16 de noviembre de 2017 Evaluado: 18 de noviembre de 2017 Aprobado: 10 de diciembre de 2017

(C) La revista. Publicado por Universidad de San Martín de Porres, Perú. (c) вr Licencia de Creative Commons Artículo en acceso abierto bajo términos de Licencia Creative Commons Atribución 4.0 Internacional. (http://creativecommons.org/licenses/by/4.0/)

\section{ORCID iDs}

Luis Arteaga-Temoche Carmen Isolina Ayala-Jara Ericson Felix Castillo Saavedra Luis Ernesto Seclén-Ayala Junior Merino Ramírez David Simón Cruz Aníbal Trujillo Gallardo Rómulo Shimizu Varas Jhoel Zúñiga Luna Guillermo Vallejo Zárate Joseph Zambrano Quispe Jesús Julca Carranza Fernando Samamé Minchón Nicolás Mattos Campos Kevin Aldave Lázaro Henry Charcape Aliaga Antonio Meléndez Vargas https: / /orcid.org/0000-0003-3260-9411 https://orcid.org/0000-0002-4926-6497 https://orcid.org/0000-0002-9279-7189 https://orcid.org/0000-0001-9855-7584 https://orcid.org/0000-0003-1851-765X https: / / orcid.org/0000-0002-4221-7967 https://orcid.org/0000-0002-7402-1651 https://orcid.org/0000-0002-5350-5059 https://orcid.org/0000-0002-6701-3995 https: / / orcid.org/0000-0002-8892-8588 https: / / orcid.org/0000-0003-4301-3955 https://orcid.org/0000-0002-7054-9993 https: / / orcid.org/0000-0002-7724-6610 https://orcid.org/0000-0002-7010-1558 https://orcid.org/0000-0001-9277-4780 https://orcid.org/0000-0001-8156-6329 https://orcid.org/0000-0001-6867-6515 